\title{
EFFECT OF INTERVENTION ON KNOWLEDGE AND ATTITUDE TOWARDS PLAGIARISM AMONG POST- GRADUATE STUDENTS IN BANGLADESH - A PILOT STUDY
}

\author{
SHAMIMA PARVIN LASKER* \& DARRYL MACER
}

\begin{abstract}
An attempt to tackle plagiarism locally, an exercise was developed and evaluated by pre-test and post-test questionnaire on 50 post-Graduate medical students at Department of Public Health \& Informatics, Bangabandhu Sheikh Mujib Medical University, Bangladesh in 2017 to understand learner's understanding regarding plagiarism. The comparative data between pre and post-test have highlighted a general lack of understanding of the basic concept of plagiarism and how to avoid plagiarism which improved after the intervention. For the question how to prevent plagiarism, before intervention, only $36 \%$ answered that a paraphrased sentence should be referenced. However, after intervention, responses to the same question significantly increased to $72 \%$. Likewise, pre-intervention for a question of whether an article can be submitted to another journal if the decision is delayed, almost half of the students (48\%) were not sure what should to do. But after intervention, all respondents $(100 \%)$ understood that an article cannot be submitted to another journal if decision delayed. For a question of making two or three articles from same thesis/research with same introduction and method, all most half of the respondent (46\%) answered "yes" and approximately half do not know the answer (40\%) before intervention. However, after the intervention all respondents (100\%) felt they should not make two or three articles with same introduction or methods. Also, after intervention all respondents (100\%) felt self-plagiarism is taking paragraph/picture from own article without reference. These results indicate that the intervention of plagiarism education improved the knowledge of this group of post-graduate medical students.
\end{abstract}

Keywords: Copy-cut-paste; Plagiarism; Publication ethics

\section{INTRODUCTION}

The World Association of Medical Editors (WAME) defines plagiarism as "the use of others published and unpublished ideas or words (or other intellectual property) without attribution or permission and presenting them as new and original rather than derived from existing source" (WAME 2018). Plagiarism is actually "a multifaceted and ethically complex problem" (Council of Writing Program Administrators 2008). Language incapability, level of scholarly engagement, lack of understanding of academic integrity, culture, racism, media scandal and institutional governance are the main causes of plagiarism (Bretag 2005). However, plagiarism is a deception and violations of the contract between the reader and the writer as the writer misleads the reader giving impression that he is the originator of that idea (Roig 2002). So "the concept of plagiarism has criminal connotations" (Angelil 2000). Therefore, consequences of plagiarism are grave, many lose their degrees or jobs for their transgressions (Standler 2000). As for example, renowned French physicist and President of the Institute for Advanced Studies for Science and Technology, Étienne Klein lost his post after allegations of plagiarism 
(Enserink 2017). Forward Prize was withdrawn from CJ Allen when it was publicized that he had plagiarized some of his past work (Forward Art Foundation 2017). Same regulation is applied to all members of the academia including professors, students, and administrators (Roig 2002). However, a survey of MaCaby of Rutgers University on 16,000 students of 47 fields from 31 reputed USA and Canada universities reported that of $56 \%$ of students have plagiarized at least once in life (Graves, 2008). In another survey analyzing 4,232 articles, published in the databases of PubMed and Web of Science (WoS) found that of $22 \%$ article were plagiarized (Fang, Steen \& Casadevall 2012). Nature published a news in 2010, that 23 percent of submitted articles in one of its journals were rejected because of plagiarism (Sophia 2010). Plagiarism is increased because of concepts of intellectual property and copyrights are not well understood (Badea 2017; Mohammad et al. 2015). Many academics plagiarize often because they aren't sure what constitutes plagiarism and how to avoid plagiarism (Rennei 2001). Insufficient education and inconsistent in enforcement, plagiarism still prevails throughout world. No data is available from Post-Graduate Medical students in Bangladesh. Therefore, piloting was done on 50 post-graduate medical students to examine their understanding regarding plagiarism.

\section{METHODOLOGY}

A descriptive, cross-sectional study was done between July and December 2017 at the Department of Public Health \& Informatics, Bangabandhu Sheikh Mujib Medical University, Bangladesh. It had two parts. First part was a retrospective normative research part for the development of a text manual on plagiarism. The second part was a cross-sectional survey through a workshop. It was a pilot study. The ethical clearance was obtained from IRB of Bangladesh Bioethics Society.

The text resource on plagiarism was based on literature review. Module consists of different component of plagiarism e.g., history, definition, classification, consequences, causes and how to avoid it. PubMed, Google Scholar, Embase, Hinary, online library and Web of Science were the possible search engine for literature. Articles published in English were reviewed only. Articles from 2000 to 2017 were searched to view the recent data. Key words for search articles were copy, cut-paste, plagiarism, and publication ethics.

The cross-sectional survey was done by a self-administered, structured pre-test and post-test questionnaire to understand the knowledge and attitude of the students on plagiarism. For this purpose, 50 post-graduate medical students were taught the text module over a period 3-hour interactive class using lecture, case study, video, and exercise. Before introduction of the module students were evaluated by pretest questionnaire. After completion of teaching on plagiarism, students were evaluated again by post-test questionnaire. The questionnaire contained 22 questions.

The questionnaire was validated by applying feedback form three post-graduate. Changes were made to the final questionnaire according to comments and criticisms of students. Students took approximately 10 minutes to complete the questionnaire. The questionnaire consisted of two parts: The first part concentrated on obtaining demographic data about the age, sex, and educational qualification of participants; number of publications, course or training on plagiarism, information about some international organizations working for plagiarism e.g. ICMJE (International Committee of Medical Journal Editor), COPE (Committee of Publication Ethics), WAME (World Association of Medical Editors), ORI (Office of Research Integrity) and some name of similarity detection software e.g., Ithenticate, Turnitin, Crossref. 
The second part was dedicated to a self-assessment of the knowledge of each respondent regarding plagiarism. Statements were concentrated to copy pasting in their article, duplication publication, meaning of self-plagiarism, fabrication, and falsification as well as strategies how to prevent plagiarism. To judge the knowledge of how to prevent plagiarism had multiple choice question. Skills were assessed by 3 stage Likert scale 'yes', 'no or 'don't know'.

After post-test, post-graduate medical students were asked to write one or two pages writing in any subject matter and return one week after intervention. There writings were evaluated by Ithenticate to understand their skill on practicing publication ethics. Written consent was obtained from the students prior to start intervention. No names or identifying information was included in the self-administered questionnaire to assure anonymity. All the questionnaire and informed consent form were stored in a secured place under locked and key. Only the post-graduate medical students who were willing to participate the workshop on plagiarism were included in this survey. Absentee students of this workshop were excluded from this study.

Sample were collected purposively according to the selection criteria where marginal error-5\%, CI-95\%, response distribution-50\%. Data was analyzed using IBM SPSS version 20 software and MS-Excel 2007. Descriptive analyses were done for all the data. Demographic and the knowledge of plagiarism variables were analyzed by frequency and percentage distribution. To test the differences in frequencies between pre and post-test, Chi-squared test was used. $P<0.05$ was considered statistically significant. No questionnaire was included for analysis when it was not properly filled out.

\section{RESULTS AND DISCUSSION}

There were $11(22 \%)$ male and 39 (78\%) female among 50 respondents. The mean age of the respondents was $30.24(95 \%, \mathrm{CI}=26-33)$. Respondents were currently writing their thesis. They did not have any previous course or training on plagiarism. There was no provision for systematic education on plagiarism by the institution. They learn plagiarism from their teacher for a certain extend during their post graduate course. No one had any publication before.

At a question of meaning of ICMJE, COPE, WAME and ORI, no participants (100\%) answered the meaning of ICMJE and WAME, but few students could answer the meaning of COPE (26\%) and WAME (14\%) before workshop attended. After intervention, all student $(100 \%)$ could answer the meaning of ICMJE, COPE, WAME, and ORI. The difference of knowledge between the before and after workshop attended was highly significant (Table 2). For a question of whether they had heard the name of plagiarism checker software e.g., Ithenticate, Turnitin, Crossref. Before workshop attended only some student could answer the meaning of Ithenticate $(34 \%)$, Turnitin (48\%), and Crossref (16\%) respectively. However, after workshop attended, all (100\%) respondents felt they were familiar with the plagiarism checker software. This difference was highly significant (Table 2). Current situation of post-graduate medical students at the Department of Public Health \& Informatics, Bangabandhu Sheikh Mujib Medical University, Bangladesh is consistent with European Union. Foltýnek at al. (2014) identified that most of the students of European union are not sure about plagiarism before enrollment at their master's/PhD degree. Only $20 \%$ of students become aware of plagiarism before entering masters or PhD degree (Foltýnek at al. 2014). 
Table 2: Comparison on few general questions before and after intervention $(\mathrm{N}=50)$.

\begin{tabular}{lcccccc}
\hline $\begin{array}{l}\text { Do you know } \\
\text { the Meaning } \\
\text { of }\end{array}$ & \multicolumn{2}{l}{ Before Workshop Attendance } & After Workshop Attendance & $X^{2}$ & $p$-value \\
\cline { 2 - 5 } & Know & Don't Know & Know & Don't Know & & \\
\hline ICMJE & $0 \%$ & $100 \%$ & $100 \%$ & $0 \%$ & 100.000 & $<0.001$ \\
COPE & $26 \%$ & $74 \%$ & $100 \%$ & $0 \%$ & 58.730 & $<0.001$ \\
ORI & $0 \%$ & $100 \%$ & $100 \%$ & $0 \%$ & 100.000 & $<0.001$ \\
WAME & $14 \%$ & $86 \%$ & $100 \%$ & $0 \%$ & 75.439 & $<0.001$ \\
& & & & & & \\
Ithenticate & $34 \%$ & $68 \%$ & $100 \%$ & $0 \%$ & 49.254 & $<0.001$ \\
Turnitin & $48 \%$ & $52 \%$ & $100 \%$ & $0 \%$ & 35.135 & $<0.001$ \\
Crossref & $16 \%$ & $84 \%$ & $100 \%$ & $0 \%$ & 72.414 & $<0.001$ \\
\hline
\end{tabular}

$p$-value at the level of $<0.05$ is significant.

For the question of copy-cut-paste in their article, before intervention only $8 \%$ of students claimed that they plagiarized in their writing. However, after the educational intervention $12 \%$ of students admitted that they plagiarized in their writing (Figure 1). After education they came to know that one third of academics of USA plagiarized once in life (Graves, 2008), this might influence them to confess the truth. However, our study revealed that most of the post-graduate medical students $(88 \%)$ were not indulge in plagiarism during their past academic career. A survey of impact of plagiarism in Higher Education Across Europe (IPPHEAE) proposed that more than 50\% students who admitted to plagiarism were come from Lithuania, Greece, and Romania. However, less than 15\% students who admitted to plagiarism were come from Czech Republic, Germany, Latvia, Slovakia, and Slovenia. It cannot be concluded that students who admit or deny their own plagiarism were honest (Folynek \& Glendining 2015). Only we can say that the sensitization of students to confess the truth after workshop attended were increased. This study also revealed that male $(10 \%)$ plagiarized significantly higher than female $(2 \%)$, which is consistence with the result of Razi (2015). He found that the one third of male students' papers $(31.25 \%)$ were rejected due to plagiarism in comparison with female students (7.14\%) (Razi 2015).

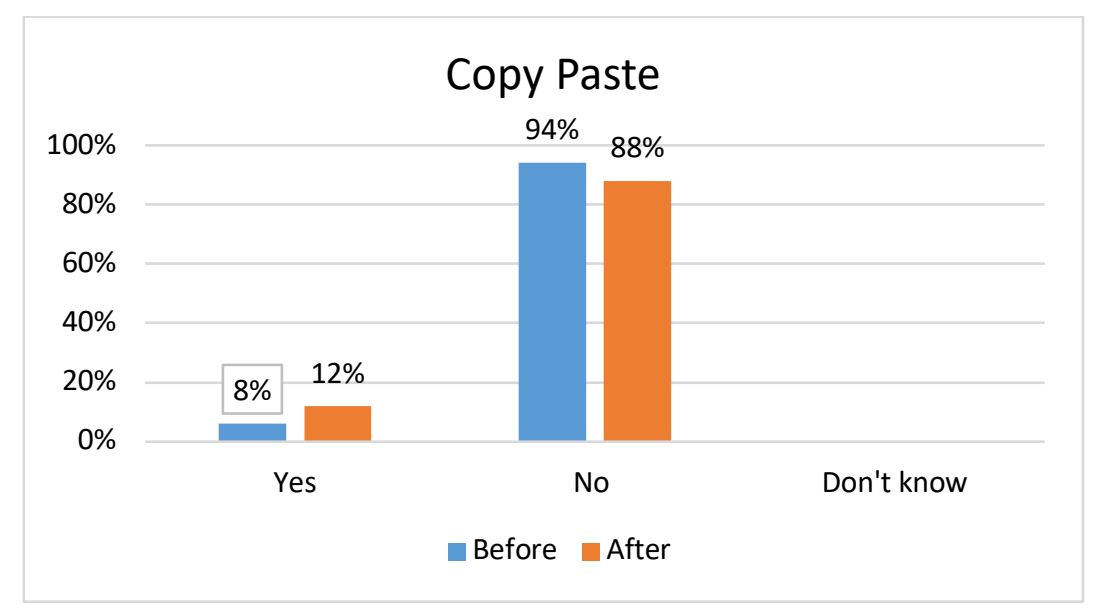

Figure 1. Comparison between before and after intervention at a question of copy paste in writing $(n=50)$.

Likewise, for the question how to prevent plagiarism, in pre-intervention, students were divided in their opinion. Only one third (36\%) answered that the sentence should be paraphrased with reference. Half of the respondents (52\%) answered that the sentence should be kept within quotation with reference. Only a quarter (28\%) answered both $b$ and $d$ (where b $=$ paraphrase and references and $\mathrm{d}=$ quotation and references) in pre-intervention group 
respectively. But after intervention, respondents (72\%) were significantly higher to choose to answer $b$ (paraphrase and references) and $d$ (quotation and references) (Figure 2). This result was consistent with report of Folynek and Glendining (2015). They proposed that most of the students from Latvia, Bulgaria, Romania, Lithuania, and France were not aware that without quotation and reference constitutes plagiarism (Folynek \& Glendining 2015). However, their research does not include any intervention of plagiarism education. On the other hand, our research was interventional study by providing education on plagiarism by an interactive workshop. After intervention, most of the respondents (72\%) understood how to prevent plagiarism. It indicated that students needed publication ethics education to prevent plagiarism.

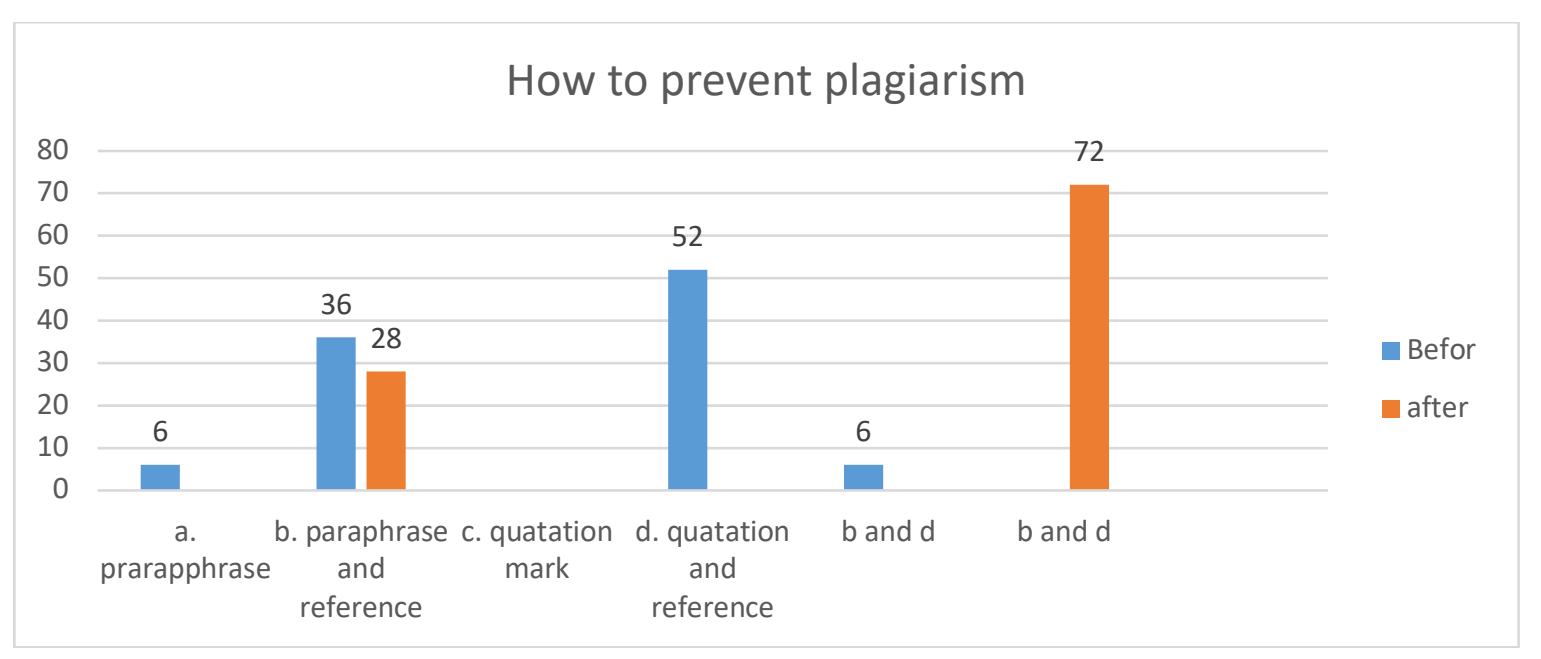

Figure 2. Comparison of knowledge on plagiarism before and after intervention $(\mathrm{N}=50)$.

Table 3 shown the comparison between pre and post intervention results at some question on what plagiarism constitute. In pre-intervention, at a question of whether article can be submitted to another journal if the decision is delayed. Almost half of the students $(48 \%)$ were not sure what should to do. But after intervention, all the respondents (100\%) felt articles cannot be submitted to another journal if decision delayed. This difference was highly significant $(<0.001)$. Similarly, at a question of whether same article can be published in two or more languages, before intervention, only less than half (40\%) respondents felt they cannot publish same article into another language. However, after intervention all the students $(100 \%)$ significantly felt that they cannot publish same article into another language $(<0.001)$. For a question of making two or three articles with same introduction and method from same thesis/research, before intervention all most half of the respondent (46\%) answered "yes" and approximately half do not know the answer (40\%). However, only few (14\%) respondents felt they cannot make two or three articles with same introduction and method from same thesis/research. But after intervention all respondents (100\%) felt they should not make two or three articles with same introduction or methods. We did not find any literature to compare our result.

However, most journals consider article in a journal that has not been published elsewhere (Cris 2007). Author(s) also certify that article has not been published or being accepted for publication elsewhere in any language (Seong et al. 2002). This rule is maintained not to skew up redundant publication, not to include more than one meta-analysis (Cris 2007). Submitting a paper to multiple journals at the same time by disregarding instructions to authors is considered a violation of publication copyright (Cris 2007). The standard practice for publication is to submit only in a single journal (Roig 2002). Duplication publication is 
retracting more quickly than other misconduct and it is the second highest misconduct for retraction (Steen, Casadevall \& Fang (2013).

The due to widely known case of Hwang Woo Suk's, scientific misconduct in 2006, Korean Research Foundation was actively engaged in educational activities on publication ethics. In 2009, it was seen that duplication publication in Korea was gradually decrease from $7.2 \%$ to $1.2 \%$ between 2006 and 2009. Publication ethics contributed greatly to the national achievements (Kim et al 2014). We understand from Korean Research Foundation policy to educate their people to in publication ethics to achieve the good publication practice.

Regarding the question of retraction of fabricated article, less than half (48\%) felt article should be retracted if it is fabricated. But after intervention all respondent $(100 \%)$ felt article should be retracted if fabricated. These results were highly significant $(<0.001)$.

Regarding self-plagiarism, our study shown that before intervention, most of the $(80 \%)$ participants felt that taking paragraph/picture/graph from own their article without reference is called self-plagiarism. On the other hand, research from Australia has shown that over $60 \%$ of authors reused the text from their previous publication without appropriate references (Bretag \& Mahmud 2009). We did not ask the students regarding the question whether they reuse their text without reference from their previous writing. But we can hypothesize that medical students at the Department of Public Health \& Informatics, Bangabandhu Sheikh Mujib Medical University, Bangladesh had knowledge of self-plagiarism before intervention. However, after intervention all respondents (100\%) felt that online article is easy to identify plagiarism.

Table 3: Comparison between before and after education on attitude to plagiarism $(\mathrm{N}=50)$.

\begin{tabular}{|c|c|c|c|c|c|c|c|}
\hline \multirow[t]{2}{*}{ Question } & \multicolumn{3}{|c|}{ Before Workshop attendance } & \multicolumn{3}{|c|}{ After Workshop attendance } & \multirow[t]{2}{*}{$p$-value } \\
\hline & Yes & No & $\begin{array}{l}\text { Don't } \\
\text { know }\end{array}$ & Yes & No & $\begin{array}{l}\text { Don't } \\
\text { know }\end{array}$ & \\
\hline $\begin{array}{l}\text { Do you think one article can } \\
\text { submit to another journal if } \\
\text { delayed? }\end{array}$ & $6 \%$ & $46 \%$ & $48 \%$ & - & $100 \%$ & - & $<0.001$ \\
\hline $\begin{array}{l}\text { Do you think same article can be } \\
\text { published in another language? }\end{array}$ & $26 \%$ & $40 \%$ & $34 \%$ & - & $100 \%$ & - & $<0.001$ \\
\hline $\begin{array}{l}\text { Do you think two or three article } \\
\text { can be made from a } \\
\text { research/thesis? }\end{array}$ & $46 \%$ & $14 \%$ & $40 \%$ & - & $100 \%$ & - & $<0.001$ \\
\hline $\begin{array}{l}\text { Do you think fabricated writing } \\
\text { should be retracted? }\end{array}$ & $48 \%$ & $12 \%$ & $40 \%$ & $100 \%$ & - & - & $<0.001$ \\
\hline $\begin{array}{l}\text { Do you think online article is easy } \\
\text { to identify plagiarism }\end{array}$ & $86 \%$ & $8 \%$ & $6 \%$ & $100 \%$ & - & - & $<0.001$ \\
\hline $\begin{array}{l}\text { Self-plagiarism is- taking } \\
\text { paragraph/picture/graph from own } \\
\text { article without reference. }\end{array}$ & $80 \%$ & $16 \%$ & $4 \%$ & $100 \%$ & - & - & $<0.001$ \\
\hline
\end{tabular}

After evaluating the writing of postgraduate medical students by ithenticate subsequently one week of intervention, it was seen that all the students $(100 \%)$ did not plagiarized in their writing. It is assumed that their attitude and skill on practicing publication ethics had increase. Our results shown that the post graduate medical student at the Department of Public Health \& Informatics, Bangabandhu Sheikh Mujib Medical University, Bangladesh has little knowledge on plagiarism. Intervention of plagiarism education improved their knowledge, skill and attributed. This result is consistent with report of the Bretag et al. (2010). They said that one in five postgraduate research students in Australia had never heard of academic integrity (Bretag et al. 2010) because most of the postgraduate students in Australia did not receive adequate training on publication ethics (Mahmud \& Bretag 2013). 
There are certain limitations in the present survey. This is a questionnaire-based survey and hence the results rely upon the replies that were received. However, as this is a first and pilot study from Bangladesh, an effort to capture the existing situation of the level of knowledge on plagiarism in ethical scientific writing in the country. Hence it needs to be validated through further study by undertaking with large number of participants and more duration of time for training/workshop in the near future. The sample size of this study is limited. It may not represent the national scenario. All the components of plagiarism had not been explored to the same extent.

\section{CONCLUSION}

Proposed text module on plagiarism had tremendously impact on post-graduate students. Students' knowledge and attitude on plagiarism were significantly changed. Intervention of plagiarism education were improved the knowledge of students at the Department of Public Health \& Informatics at Bangabandhu Sheikh Mujib Medical University in Bangladesh. More workshops are needed on the text on plagiarism to finally conclude substantial remark of success of this module on plagiarism.

\section{REFERENCES}

Angelil C.S. 2000. Stolen Language? Plagiarism in Writing. Essex: Pearson Education Limited.

Badea, O. 2017. Do medical students really understand plagiarism? Case study. Rom J Morphol Embryol 58(1): 293-296.

Bretag, T. 2005. Implementing plagiarism policy in the internationalized university, Part 3 in Developing internationalism in the internationalized university: A practitioner research project, Doctor of Education thesis, Division of Education, Arts and Social Sciences, University of South Australia.

Bretag, T., and Mahmud, S. 2009. A model for determining student plagiarism: Electronic detection and academic judgment. Journal of University Teaching and Learning Practice 6 (1): 48-60.

Bretag, T., Walker, R., Green, M., East, W., James, J. C. 2010. Academic integrity standards: aligning policy and practice in Australian universities. Successful Priority Projects proposal to the Australian Learning and Teaching Council.

Chris, G., Elizabeth, W., Alyson, B., Suzan, F., Diane, Andrew, R. 2007. Best Practice Guidelines on Publication Ethics: A Publisher's Perspective Journal Compilation. $J$ Clin Pract, 61: 1-211.

Council of Writing Program Administrators. 2008. The WPA Statement on Best Practices Defining and avoiding plagiarism. Retrieved from www.wpacouncil.org (Accessed 12 June 2017).

Enserink, M. 2017. French physicist accused of plagiarism seems set to lose prestigious job. Science. $\quad$ http://www.sciencemag.org/news/2017/04/french-physicist-accused plagiarism-seems-set-lose-prestigious-job. (Accessed 1o May 2017).

Fang, F.C., Steen R.G., and Casadevall, A. 2013. Misconduct accounts for the majority of retracted scientific publications. Proc Natl Acad Sci 109: 17028-17033.

Foltýnek, T. and Glendinning, I. 2015. Impact of policies for plagiarism in higher education across Europe: results of the project. Acta Universitatis Agriculturae et Silviculturae Mendelianae Brunensis 63 (1): 207-216. 
Foltýnek, T., Kravjar, J. and Glendinning, I. 2014. Case Study: Policies, Strategies and Responses to Plagiarism in Slovakia", Journal on Efficiencyand Responsibility in Education and Science 7(1): 19-25.

Forward Arts foundation. 2017. Retrieve from http://www.forwardartsfoundation.org/poet/c-jallen/ (Accessed 12 June 2021).

Graves, L. 2008. Which Types of Students Cheat Most? US News. https://www.usnews.com/education/articles/2008/10/03/which-types-of-studentscheat-most (Accessed 12 June 2021).

Kim, S.Y., Bae, C.W, Hahm, C.K., Cho H.M. 2014. Duplicate publication rate decline in Korean Medical Journals. J Korean Med Sci 29(2): 172-5.

Mohammed, A.A.R., Shaaban, O.M., Dalia, G., M., Attellawy, H. N., Makhlof, A., and Albasri, A. 2015. Plagiarism in medical scientific research. J Taibah University Medical Sciences 10(1): 6-11.

Mahmud, S. and Bretag, T. 2013. Postgraduate research students and academic integrity: 'It's about good research training'. Journal of Higher Education Policy and Management 35: 432-443.

Razi, S. 2015. Development of a Rubric to Assess Academic Writing Incorporating Plagiarism Detectors. SAGE Open, $1-13$.

Rennie, S. C., and Crosby, J. R. 2001. Are "tomorrow's doctors" honest. Questionnaire study exploring medical students' attitudes and reported behavior on academic misconduct? BMJ 322: 274-5.

Roig, M. 2003. Avoiding plagiarism, self-plagiarism, and other questionable writing practices: A guide to ethical writing. ORI, pp 1-63. Retrieved from http://ori.hhs.gov/education/products/roig_st johns/On\%20ethical\%20writing.html (Accessed 12 June 2017).

Sophia, L. 2010. Journal review process increasingly includes check for plagiarism. Chron High Educ. Retrieved from http://chronicle.com/blogs/wiredcampus/journal-reviewprocess-increasingly-includes-checkfor-plagiarism/25420. (Accessed 10 May 2021).

Standler, R. B. 2000. Plagiarism in Colleges in USA. Retrieved from http://www.rbs2.com/plag.htm. (Accessed 1 June 2021).

Hwang, S. S., Song, H. H, Baik, J. H., Jung, S. L., Park, S. H. 2003. Researcher Contributions and Fulfillment of ICMJE Authorship Criteria: Analysis of Author Contribution Lists in Research Articles with Multiple Authors Published in Radiology 226(1): 16-23.

WAME. 2018. Recommendations on Publication Ethics Policies for Medical Journals. Retrieve from http://www.wame.org/about/recommendations-on-publication-ethicspolicie (Accessed 1 June 2021).

\section{SHAMIMA PARVIN LASKER* \\ Shahabuddin Medical College \\ Dhaka, Bangladesh}

DARRYL RJ MACER

Former UNESCO Regional Adviser of Asia and Pacific

American University of Sovereign Nations, USA

*Corresponding author: splasker04@yahoo.com

Received: 23 August 2021 / Accepted: 14 October 2021 / Published: 20 November 2021 